\title{
Could Government Measures Crowd Out Grassroots Philanthropy? Empirical Evidence from an Education Crowdfunding Platform
}

\author{
Anqi (Angie) Wu, Aravinda Garimella, Ramanath Subramanyam* \\ University of Illinois at Urbana-Champaign \\ \{anqiwu2, aravinda,rsubrama\}@illinois.edu \\ * The authors contributed equally to this work.
}

\begin{abstract}
Over the last two decades, grassroots altruism, enabled through platforms such as DonorsChoose.org, has resulted in successful funding of innumerable and essential public school projects across the country. While such channels become critical fundraising mechanisms, there is an unintended possibility of crowding out of these sources by governmental initiatives which aim to shed light on, and address public school resource deficits. In this study, with a focus on major public policy announcements, we examine whether there is an unintended effect of external measures, such as the signing of the Every Student Succeeds Act (ESSA), on grassroots altruism, which is possible to examine on online philanthropy platforms. We surmise that, in such platforms, donors could become complacent and take comfort in the cognizance of an external agency addressing the problems they care about - we call this the savior effect. Importantly, from our analysis of panel data on the platform, we find that the savior effect: (a) results in declined donations toward under-served public school projects on the platform, and (b) makes donations more local, disproportionately impacting schools with high concentrations of low-income and minority students, which receive fewer instructional resources to begin with. Our work has important policy implications for public schools, donor communities, and online fundraising platforms.
\end{abstract}

\section{Introduction}

Equity and adequacy in funding are prerequisites for the provision of equal educational opportunity [1]. However, it is a widely-established concern that public schools in the United States of America are both underfunded and inequitably funded [2]. Public school educators continue to dip into their own pockets to the tune of at least $\$ 459$ every year [3], with teachers in high-poverty schools shelling out more of their own money. Limited budgets and red tape have led many teachers to seek outside funds for classroom projects.

Recently, philanthropic crowdfunding, enabled through platforms like DonorsChoose.org, has catalyzed teachers efforts to generate resources to address resource shortages. In addition to providing a new way to fund educational needs, a notable difference with such platforms ${ }^{1}$ is that teachers drive decisions about what to raise funds for and how much to raise. A teacher can set up a campaign in a matter of minutes and receive funding for basic classroom supplies, curricular materials, technology, enrichment programs and a host of other expenses. When it works, crowdfunding can provide fast money that can directly get into the hands of teachers with few barriers to entry. However, such platforms are perceived to have contrasting effects on public education. At one end, they can serve underfunded schools and provide them access to private funding. At the other extreme, they can provide a mechanism for schools serving affluent communities to further access additional capital, and increase the 'resource-divide' in schools. The overall impact of such platforms has been increasing over time. For example, DonorsChoose recently highlighted that close to a billion dollars (USD 971M) have been raised over the last two decades with funds wholly going towards teacher-led and student-led projects serving school needs ${ }^{2}$. In essence, online platforms have evolved to become a non-trivial fundraising mechanism for schools.

Meanwhile, school districts, boards, state and federal policy makers have been making efforts to improve and promote transparency of school governance. Periodically-reauthorized federal initiatives (Elementary and Secondary Education Act or ESEA: 1965, No Child Left Behind or NCLB: 2002, Every Student Succeeds Act or ESSA: 2015) have set federal standards for accountability, proficiency,

\footnotetext{
${ }^{1}$ DonorsChoose.org is one of many platforms used by educators to raise funds online. Other leading platforms used by teachers include GoFundMe.org, AdoptAClassrooom.org and Livingtree.

${ }^{2}$ Source: https://www.donorschoose.org/about/impact.html
} 
and improvements - but allowed implementation flexibility across state, local, and school district boundaries. At some level, each of these federal initiatives (ESEA, NCLB, ESSA) is concerned about (a) students in poverty, (b) minorities, and (c) students receiving special education services, among other priorities. Specifically, ESSA was signed into law in December 2015, wherein each state was given further flexibility through federal-state negotiations on accountability practices, proficiency standards, and school-improvement processes - within a federal framework. However, among several actions, it requires states, for the first time, to break down how much districts spend on each school [4].

Our research interest is at the junction of these two phenomena. We are specifically interested in examining whether announcements of such governmental initiatives could unintentionally influence private philanthropic donations to schools. As philanthropic crowdfunding emerges as a viable fundraising mechanism for teachers, external policy events of direct concern to educational institutions are likely to affect the behavior of potential donors. One key reason is that external events and news-making phenomena are critical elements of modern fundraising. Research on charitable giving (e.g., [5]) suggests that charitable giving is driven mainly by factors such as (a) awareness of need, (b) solicitation, (c) costs and benefits, (d) altruism, (e) reputation, (f) psychological benefits, (g) values, and (h) efficacy. As we examine modern online crowdfunding platforms like DonorsChoose, we believe that external events, such as a major education policy with accountability and transparency implications being passed, could noticeably affect donor perceptions, impacting some of these donation-driving factors, thereby shaping eventual donors' views and behaviors. Our study specifically examines whether such external events affect observed donor behavior, recipients, and the overall online fundraising ecosystem.

Two aspects of online platforms are critical for such altruism to work. First, on the recipient side of the platform, there need to be enterprising teachers who recognize the potential of such alternate fundraising mechanisms. Second, on the provider side, there needs to be a growing base of philanthropic donors who need to get matched to the aid-seeking projects that serve student needs. We believe this second (fragile) component, donor funding behavior, is likely to be subject to perception biases, nature and extent of news coverage, and overall vicissitudes in prevailing public opinion. If announcements of federal initiatives are followed by discernible public dialogue surrounding transparency and accountability, donor perceptions may be affected. Since donor contributions form the lifeblood of successful online crowdfunding effectiveness, we believe that it is important to examine whether donor behavior is indeed affected by such external events.

If donors perceive that (a) economy-spanning policies are already addressing issues close to their interest or (b) that a decrease in transparency and accountability implies a lower burden on schools, they could step back and focus their attention on alternate interests. We term this effect "savior effect" which represents donors' loss of zeal in times of need. Our data shows that majority of the requests are from schools catering to communities of lower socioeconomic status (SES) (see Figure 1(A)); these communities could be hurt disproportionately. Specifically of interest would be the breadth of policies such as ESSA, since there would be widespread shifts in the way schools are perceived as critical recipients. While it is possible that the entirety of contributions to such platforms could diminish, it is also conceivable that donors might simply re-align their interests within the platform to certain subsets of interests.

With the radical evolution of digital technologies and wide-spread diffusion of social media technologies, the manner in which citizens consume news and external happenings is evolving. With societal causes such as education, online communities (e.g., connection of parents, teachers, and children) could result in varied levels of awareness of public policy events and of the differential financial states of local institutions. Examining whether this differential diffusion of awareness affects the distribution of private funds is essential.

Research on philanthropy and public finance has examined the crowding out hypothesis or the question of whether government subsidies to nonprofits displaces (crowds out) private philanthropic giving to these causes. Some scholars (e.g., [6]) have predicted that complete crowding out will occur, while other work (e.g., [7]) has predicted fractional crowding out (e.g., subsidies will displace less than the amount of typical donations), a prediction that has also been supported by experimental evidence [8]. Extant research has examined the problem at the level of overall financial resource distributions, but has not examined contexts where there is no public donation but rather a macroscopic policy event or announcement that matters to the overall societal welfare.

This paper examines the savior effect by leveraging the shock of the ESSA plan being effective for each state in the school year of 2017-2018. We provide empirical evidence that addresses the two key questions: 
(1) Does the public event of ESSA being passed reduce private donations to schools? (2) Does the event redistribute private donations? Our empirical analysis starts by comparing the school raised amount and fully funded rate before and after the policy shock. We collate a 20-quarter (2015Q1 2019Q4) panel of data representing 73,303 schools, totaling 509,859 observations. This data consists of fundraising outcomes of U.S. elementary and secondary schools as crowdfunders in DonorsChoose. We combine this data with information about school demographics and characteristics such as student membership and full-time equivalents collected from National Center for Education Statistics. We find that, with the introduction of ESSA, there is a significant decline in the donations schools receive through online fundraising. We also observe that donations become more local in nature after the implementation of the act. We further stratify the schools based on their proportions of low-income and minority students and show that schools with predominantly low-income and/or minority students receive fewer online donations. Next, we utilize Google Trend to construct the measurement of the donor awareness and document that donors from states with higher awareness of ESSA give even lower amounts and allocate a larger portion of their donations locally. Our findings provide important implications for public schools, donor communities, online fundraising platforms, and policy makers, with details discussed in Section 5.

\section{Related Literature}

This paper builds on the growing body of information systems literature that studies online crowdfunding and charity donations. Previous empirical research has explored various factors within the crowdfunding ecosystem to drive the donor behavior or crowdfunding outcomes, such as characteristics of crowdfunders $[9,10]$, access to information controls [11], the social network and activities among advocates [12], and information on prior contribution behavior $[13,14]$ or charity performance metrics $[15,16]$. This study looks beyond internal drivers and contributes to the literature by providing empirical validation on an external driver, a major federal education policy being passed, to the donor behavior and crowdfunding outcomes.

There is a growing body of empirical research on education that has studied the consequence of education policies. Education policies are designed to enhance student achievement social welfare; nevertheless, previous research provides evidence on unintended consequences of education policies. For example, some researchers find no effects or negative effects on the performance of at least some groups of students attributable to NCLB [17, 18]; some observe that the NCLB has had no effect on enrollment in education majors and even reduced the percentage of education degrees awarded by postsecondary institutions [19]; and some show that while flexibility and autonomy might be key components of ESSA, under-resourced districts and schools might not experience such flexibility and autonomy due to a lack of resources [20]. In this study, we enhance the understanding of ESSA and identify its another unintended consequence in fundraising performance, that is, crowding out private crowdfunding donations.

In the context of private donations, there has been related research that has examined the crowding out effect of government support in non-profit settings (e.g., $[21,22])$. While evidence regarding the relationship between government financial support and private donations has not been conclusive, there has been even less discussion on the role of intermediaries (such as crowdfunding platforms) in the relationship between government support and private donations (e.g., [23]). Since external shocks such as governmental accountability-related initiatives do not correspond to, or have direct effects on, financing structure of schools, there is considerable value in examining such relationships, especially since private giving through non-profit technology platforms and its relationship to governmental efforts is poorly understood. Similarly, there is very minimal work that examines macro-policy shocks on private donation towards public welfare initiatives. Our work on the role of ESSA contributes to his gap in our understanding of non-economic shocks on private donation behavior through platforms, such as Donorschoose.

An alternate stream of research in the area of volunteering also contributes to our understanding by focusing on macroscopic views on public goods and social volunteering. There are two perspectives in this stream. The substitution-based view is that voluntary action originates from an unsatisfied demand for collective goods that is not met by the government (e.g., [24]). If the government performs these tasks, the engagement of private volunteers in the society is rendered unnecessary and will consequently decrease. In contrast to this view is a complementariness-based view between governmental initiatives and private voluntary action [25]. In this view, governmental effort does not replace civic activities, but rather remains complementary to civic engagement [26]. Our examination will help discover the role of donation 
platforms and private economic donation behavior when governmental policy shocks are involved.

\section{Research Context and Data}

The research context in our study is DonorsChoose.org, a crowdfunding platform based in New York City, NY, which was established in March of 2000. It is a nonprofit organization (NPO) that allows individuals to donate directly to public school classroom projects. In particular, DonorsChoose enables teachers to request materials and resources for their classrooms and makes these project requests available to individual donors through its website. Similar to other crowdfunding platforms, project pages contain a description by the teacher and further information about the concrete needs, the school, location, poverty level, subject, grade level, how many students are impacted by this project, and how many donors have contributed to this project. If a partially funded project expires (i.e., fails to attracted full funding within a four-month period), donors get their donations refunded as account credits, which they can use towards other projects.

\subsection{Data}

To investigate how the external agency affects school crowdfunding performance, we obtain data and construct variables from the following sources for our main analysis:

\section{DonorsChoose.org}

2. National Center for Education Statistics (NCES): Common Core of Data (CCD)

The donation data, obtained via an API from DonorsChoose.org, provide five separate datasets at the levels of classroom projects, teachers, schools, donors and project donations. We collect donation records between 2011 to 2019. Over this period, 2,210,531 projects have been posted on DonorsChoose.org, among which 1,469,368 (66\%) were fully funded.

We obtain school demographic information, from NCES - CCD. The CCD is the Department of Education's primary database on public elementary and secondary education in the US and it manages a comprehensive, annual, national database of all public elementary and secondary schools. The database includes demographic information for schools as reported on the annual CCD School Universe Survey. The survey includes directory and status information, student membership dis-aggregated by grade, race/ethnicity and sex, full time employees by professional category, and counts of students with free/reduce-priced lunch plan. The demographic information is collected at the yearly level and it has been comprehensive since 2015 .

We collate a school-level dataset by matching the two databases with the NCES school identifier. The final matched sample consists of 73,303 unique schools which cover $68 \%$ of all the elementary and second schools in the US. In our main analysis, we focus on the period of twenty quarters from 2015 to 2019. We select this study period for three reasons. First, as mentioned earlier, the yearly demographic information of schools has been comprehensive since 2015 and is available until 2019. We expand our study period to 2011-2019 for additional analyses. Second, we use quarters rather than years as the time units to ensure that the study period covers at least five time units (quarters) before and after the policy shift, given that the ESSA was widely in effect in the school year of 2017-2018. Third, as the quarterly data provides sufficient observations, we do not break down to monthly data to avoid low variations for the yearly information of school characteristics.

\subsection{Variable Definition}

We construct a set of school-specific variables based on the unique dataset compiled from the two data sources described above. The main variables are summarized in Table 1.

\section{Dependent Variables}

We use several crowdfunding performance outcomes as dependent variables in our analysis. Our primary dependent variable, Proportion Funded, is a proportion of projects succeeded in reaching its fundraising goal [9]. Another performance outcome, Amount Raised, measured the total dollar amount raised by the school [9, 27]. We split Amount Raised into two additional dependent variables - Local Amount and Outside Amount based on the locations of the schools and donors. Specifically, Local Amount measures the contribution amount raised from donors located in the same first three digits of zip code as the school; Outside Amount measures the contribution amount raised from donors outside the area with the three-digit zip code. We choose the first three digits of zip codes rather than five digits as the locational unit because, while five-digit zip codes are feasible for schools, geographic information of donors is available only at the three-digit zip code level. We also use the state as an alternative metric to distinguish local and non-local donors.

\section{Key Independent Variable}


Table 1. Variables and Summary Statistics

\begin{tabular}{|c|c|c|c|c|c|c|c|}
\hline Variable & Description & Source & Mean & St. Dev. & Median & \# Schools & \# Obs. \\
\hline Amount Raised & Total dollar amount raised through the platform & DonorsChoose & 1294.70 & 2726.40 & 601.10 & 73303 & 509859 \\
\hline Proportion Funded & Ratio of funded projects to total projects & DonorsChoose & 0.65 & 0.40 & 0.83 & 73303 & 509859 \\
\hline Local Amount & Dollar amount contributed by local donors & DonorsChoose & 321.70 & 792.34 & 100.00 & 73303 & 509859 \\
\hline Outside Amount & Dollar amount contributed by non-local donors & DonorsChoose & 973.10 & 2363.62 & 429.30 & 73303 & 509859 \\
\hline Num. Projects & Number of projects posted on the platform & DonorsChoose & 3.10 & 4.95 & 2.00 & 73303 & 509859 \\
\hline Proportion Basic & Ratio of basic projects to total projects & DonorsChoose & 0.33 & 0.40 & 0 & 73303 & 509859 \\
\hline Amount Requested & Total requested dollar amount & DonorsChoose & 2240.13 & 4464.08 & 1087.81 & 73303 & 509859 \\
\hline Low-Income & Number of Low-income students (qualified for NSLP) & CCD & 314.00 & 299.98 & 254 & 73303 & 509859 \\
\hline Minority & Number of non-white students & $\mathrm{CCD}$ & 383.80 & 392.61 & 301 & 73303 & 509859 \\
\hline Num. Students & Total student counts & CCD & 629.10 & 468.65 & 535 & 73303 & 509859 \\
\hline FTE & Full-time equivalents & CCD & 37.27 & 26.14 & 32.20 & 73303 & 509859 \\
\hline
\end{tabular}

The main independent variable in our analysis is $E S S A$, a binary indicator for the announcement of the ESSA. While the ESSA technically went into effect for the 2017-18 school year, a state could only put its plan into effect, after the U.S. Department of Education signed off on the state plan. To obtain information on the ESSA approval associated with each state, we reviewed the consolidated state plan of ESSA and recorded the date when the plan had been authorized.

\section{Control Variables}

Besides the announcement of ESSA, several other characteristics could potentially be associated with a school's crowdfunding performance, reflected in its Proportion Funded and Amount Raised. Recent empirical research has studied several of such characteristics [28, 29]. We therefore include these factors in our control variables. Specifically, we consider project-level factors - the number of projects posted by schools (Num. Projects), the project amount requested by schools(Amount Requested) and proportion of projects that schools request for their students' basic needs (Proportion Basic) ${ }^{3}$. We aggregate these project-level factors to the school-quarter level. The remaining controls can only be constructed at the school-year level. We utilize the CCD database to measure the poverty level (Low-Income) by constructing the logged number of students who are qualified for the National School Lunch Program (NSLP) ${ }^{4}$. We separately construct the logged number of full-time equivalents $(F T E)$ to indicate the utilization of school resources. We also include the school size, measured by the logged number of student membership excluding adult education (Num. Students), to control for the influence of school scale on the crowdfunding performance. In our additional analysis, we consider

\footnotetext{
${ }^{3}$ We identify basic projects by grouping project resource types related to "classroom basics", "flexible seating", "food, clothing hygiene", "books", and "reading nooks, desks storage".

${ }^{4}$ The NSLP is a federally assisted meal program operating in public and nonprofit private schools and residential child care institutions. It provides nutritionally balanced, low-cost or no-cost lunches to children each school day. https://www.fns.usda.gov/nslp/nslp-fact-sheet
}

the logged number of non-white students to assess the school minority (Minority).

\section{Empirical Analysis and Results}

While ESSA was signed in December 2015 and went into effect in the 2017-18 school year, ESSA plans for different states went into effect at different points in time, based on when the US Department of Education signed off on the state's plan. This temporal and geographic variation allows us to examine the causal effect of ESSA plan announcements on donor behavior, ruling out alternative explanations. We specifically leverage the date when each state's plan was approved as an external shock to compare donation activity before and after the shock. In this section, we first present our before-after analysis at the school level to assess the impact of ESSA authorization on the donations that schools receive through the platform. We demonstrate the robustness of our results using alternative models and variable specifications. Finally, we conduct additional analyses to examine how the impact of ESSA announcements varies across schools.

\subsection{Main Effects of ESSA Announcement: Drops in School Crowdfunding Success}

We leverage the exogenous policy shock on schools in each state as a natural experiment and use a before-after analysis to mimic a randomized experimental design and thus produce a unbiased estimate of the "treatment effect," i.e., the impact of the ESSA on school crowdfunding performance. Our model specification for the before-after analysis is as follows:

$$
\begin{aligned}
& \mathrm{Y}_{i j t s}=\beta \cdot E S S A_{j t s}+X_{i t s}^{\prime} \cdot \gamma+\text { School }_{i} \\
&+ \text { Year }_{t} \times \text { State }_{j}+\text { Quarter }_{s}+\epsilon_{i j t s} .
\end{aligned}
$$

In the equation above, $i$ denotes a school, $j$ denotes the state that the school is located in, and $t$ denotes the time period. $Y_{i j t s}$ denotes the dependent variables defined above. Because the dependent variable Amount Raised, Local Amount and Outside Amount are non-negative continuous data, we follow the convention 
Table 2. Effects of ESSA on School Crowdfunding Performance

\begin{tabular}{|c|c|c|c|c|}
\hline & \multicolumn{4}{|c|}{ Dependent variable: } \\
\hline & $\begin{array}{c}\text { Amount Raised } \\
\text { (1) }\end{array}$ & $\begin{array}{c}\text { Proportion Funded } \\
\text { (2) }\end{array}$ & $\begin{array}{c}\text { Local Amount } \\
\text { (3) }\end{array}$ & $\begin{array}{c}\text { Outside Amount } \\
\text { (4) }\end{array}$ \\
\hline$\overline{E S S A}$ & $\begin{array}{c}-0.233^{* * *} \\
(0.062)\end{array}$ & $\begin{array}{c}-0.073^{* * *} \\
(0.018)\end{array}$ & $\begin{array}{c}0.135^{* *} \\
(0.057)\end{array}$ & $\begin{array}{c}-0.341^{* * *} \\
(0.077)\end{array}$ \\
\hline Num. Projects & $\begin{array}{c}1.734^{* * *} \\
(0.049)\end{array}$ & $\begin{array}{c}0.299^{* * *} \\
(0.007)\end{array}$ & $\begin{array}{c}1.868^{* * *} \\
(0.030)\end{array}$ & $\begin{array}{c}1.815^{* * *} \\
(0.047)\end{array}$ \\
\hline Amount Requested & $\begin{array}{c}0.145^{* * *} \\
(0.021)\end{array}$ & $\begin{array}{c}-0.197^{* * *} \\
(0.004)\end{array}$ & $\begin{array}{c}0.136^{* * *} \\
(0.021)\end{array}$ & $\begin{array}{c}0.231^{* * *} \\
(0.021)\end{array}$ \\
\hline Proportion Basic & $\begin{array}{c}0.134^{* * *} \\
(0.011)\end{array}$ & $\begin{array}{c}0.022^{* * *} \\
(0.003)\end{array}$ & $\begin{array}{c}0.089^{* * *} \\
(0.010)\end{array}$ & $\begin{array}{c}0.169^{* * *} \\
(0.010)\end{array}$ \\
\hline School-Level Controls & $\mathrm{Y}$ & $\mathrm{Y}$ & $\mathrm{Y}$ & $\mathrm{Y}$ \\
\hline School, State, Year, Quarter (FE) & $\mathrm{Y}$ & $\mathrm{Y}$ & $\mathrm{Y}$ & $\mathrm{Y}$ \\
\hline Observations & 509,859 & 509,859 & 509,859 & 509,859 \\
\hline $\mathrm{R}^{2}$ & 0.478 & 0.341 & 0.497 & 0.454 \\
\hline Adjusted $\mathrm{R}^{2}$ & 0.390 & 0.230 & 0.412 & 0.362 \\
\hline
\end{tabular}

to characterize the model by $\log$ of the dependent variables. Note that while Proportion Funded is a proportion data which is appropriate to employ the fractional Probit model to estimate the model, we run the before-after analysis for Proportion Funded using the Ordinary Least Squares (OLS) model to make the results more interpretable ${ }^{5}$. ESS $A_{j t}$ is the treatment dummy variable that equals 1 if the state $j$ passed its ESSA plan at time $t . X_{i t}$ represents a vector of demographic control variables with $\gamma$ being their corresponding estimated coefficients. ${ }^{6}$ The vector School $_{i}$ contains school fixed effects, Year $_{t}$ and Quarter $_{t}$ contain time fixed effects for each time period, and State $_{j}$ contains state fixed effects. We consider the school and state fixed effects to account for potentially unobserved school and state characteristics and cluster the standard errors at the state level to further control for potential correlations in error terms. We include the year and quarter fixed effects to adjust for the unobserved temporal trends over our study period.

Table 2 presents the estimation results for the main effects of ESSA announcement on school crowdfunding performance. In columns (1) and (2), the coefficient estimates of the variable, ESSA, are significant at the one-percent level and economically large, indicating that schools that are in a state that had its ESSA plan signed are likely to have inferior crowdfunding outcomes. The results show that schools in states where ESSA signing is announced see a drop of $23 \%$ in the amount raised and a 7.3\% drop in the proportion of projects that meet their funding goals compared to schools in states where ESSA is not yet signed into effect. In summary, the announcement of ESSA signing

\footnotetext{
${ }^{5}$ We observe consistent findings when using the fractional Probit model.

${ }^{6}$ All the control variables are scaled by log-transformation except Proportion Basic.
}

is associated with a significant decline in the donations that schools receive. It appears that the knowledge of the implementation of the act diminishes the donors' drive to fund teachers' projects.

In columns (3) and (4), we report results for our second model where the dependent variables are the amounts raised from local donors and outside donors respectively. We calculate Local Amount as the contribution amount raised from donors located in the same first three digits of zip code as the school and Outside Amount as the contribution amount raised from donors outside the area with the three-digit zip code. ${ }^{7}$ The coefficient estimate of the variable, ESSA is positive in column (3), while the estimate in column (4) is negative. The results also hold if we use the state as an alternative metric to identify local/non-local donors. This suggests that schools raise more in donations from local donors and less from non-local donors after the state's ESSA plan is signed into effect.

As for the estimates of the control variables in Table 2, we observe that schools' fundraising requirements, measured by Num. Projects, Amount Requested and Proportion Basic, have significant impacts on the fundraising outcomes. One explanation for our finding could be that the introduction of the ESSA reduces and redistributes donations for schools through influencing schools' fundraising requirements. To test this explanation, we use Num. Projects, Amount Requested and Proportion Basic as dependent variables and regress them on ESSA in the before-after analysis. As shown in Figure 1(D), the insignificant coefficients of ESSA on these dependent variables indicate schools' fundrasing requirements do not change significantly after the introduction of ESSA. Alternatively stated,

\footnotetext{
${ }^{7}$ We choose the first three digits of zip codes rather than five digits as the locational unit because, while five-digit zip codes are available for schools, geographic information of donors is available only at the three-digit zip code level
} 
Figure 1. Schools Raise Funds through DonorsChoose.org
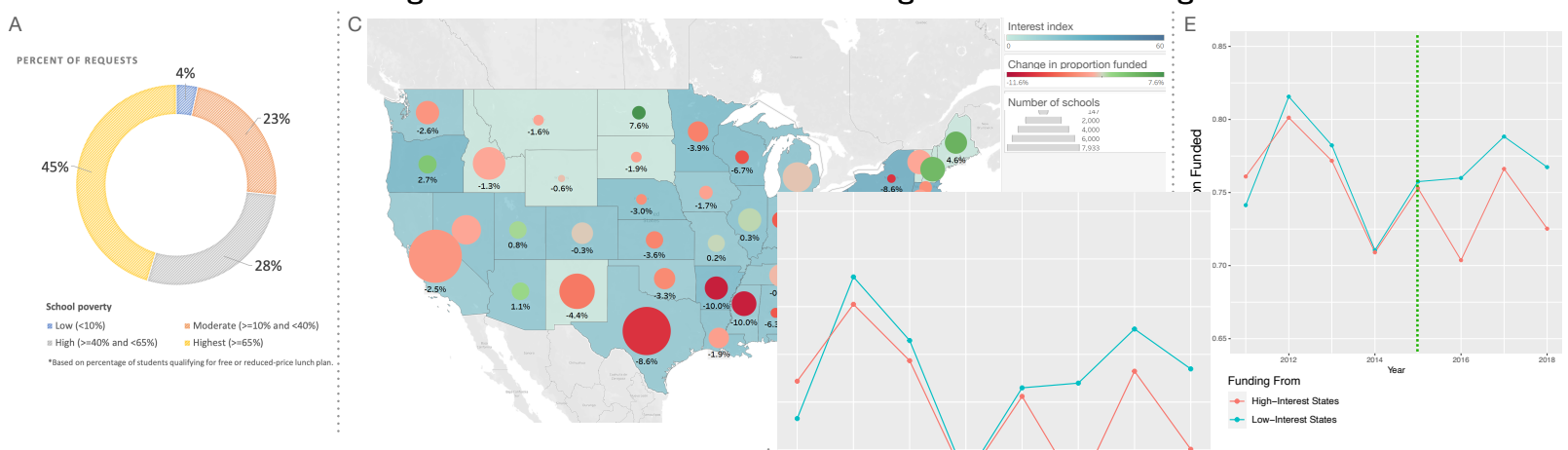

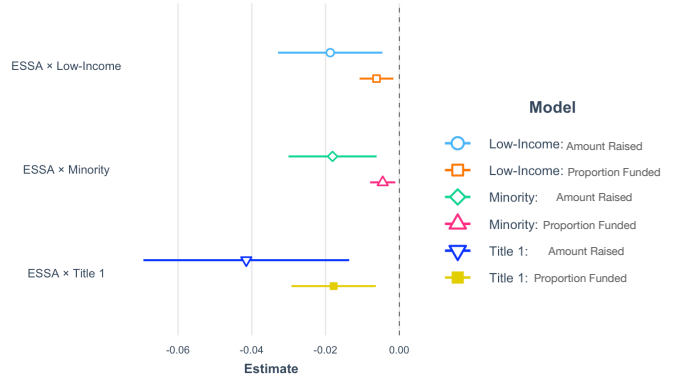

D

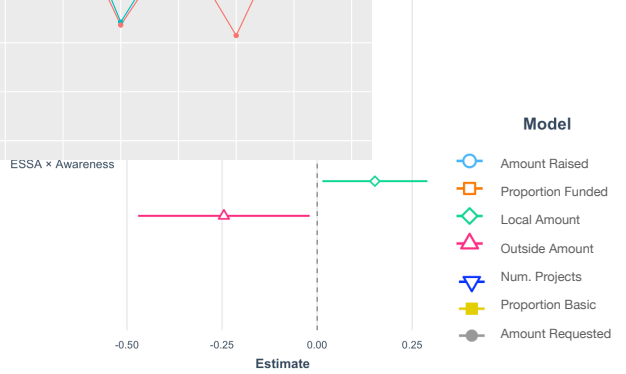

Note. (A) presents the proportion of projects by the poverty level of the school making the request, $2015-2019 ; 45 \%$ of all requests come from schools in the highest poverty bracket (in which $65 \%$ or more students receive free or reduced-price meals). (B) shows that the effects on lower SES students and Title 1 schools are even stronger (with coefficients of the interaction terms significantly negative). (C) presents donors' ESSA awareness by state (shades), percentage change in school crowdfunding performance after the signing of the ESSA state plan (circle colors: red - negative, green - positive), and the number of schools by state (circle sizes); most schools experienced a decrease in crowdfunding performance after their state plans were signed. (D) presents that coefficients of ESSA $\times$ Awareness for Raised amount, Proportion Funded, and Outside Amount are significantly negative, while the coefficients for Local Amount are significantly positive; we also observe insignificant coefficients for Num. Projects, Proportion Basic, and Amount Requested. (E) compares crowdfunding performance before and after the ESSA announcement date, Dec 10, 2015 (the green dashed line), between schools receiving donations from donors with high and low interests in the ESSA announcement; after the announcement of ESSA, schools with projects funded by high-awareness donors (red line) see a significantly decline in the percentage of projects funded as compared to their low-awareness (green line) counterparts.

the policy directly reduces and redistributes the donors' contribution to schools' projects rather than by influencing the requirements and requests from schools.

Taken as a whole, this set of results provides the first evidence suggesting that the approval of ESSA is accompanied by the worsening of crowdfunding outcomes for schools. We leverage the information about ESSA signing in this before-after analysis and conclude that ESSA announcement is associated with a noticeable decrease in crowdfunding donation amounts as well as the likelihood of a project getting funded. Interestingly, we find that donations become more local in nature after the sign-off of the act. That is, not only does the announcement affect how much people give but also how donors distribute their donations.

\subsection{Impact on Lower SES Students and Title 1 Schools}

As shown in Figure 1(A), majority of the requests are from schools receiving fewer instructional resources to begin with. To examine how the impact of
ESSA announcements varies across schools, we further stratify schools based on (1) whether a school is a Title 1 school $^{8}$ and (2) the concentration of lower SES students (measured by Low-Income and Minority card2016universal).

We respectively include interaction terms, $E S S A \times$ Low-Income, ESSA $\times$ Minority, and ESSA $\times$ Title 1 , in the model relating ESSA announcements and school crowdfunding outcomes. Figure 1(B) present results for the impact on lower SES students and Title 1 schools. The coefficients of the interaction term on the three variables, ESSA $\times$ LowIncome, $E S S A \times$ Minority and ESSA $\times$ Title1, are all negative at the five-percent level. Our results suggest that, when external shocks cause grassroots donors to contribute less than they usually do, schools with students from predominantly lower SES could be disproportionately impacted.

\footnotetext{
${ }^{8}$ Title 1 is the largest federally funded educational program, providing supplemental funds to school districts to assist schools with the highest student concentrations of poverty to meet school educational goals.
} 


\subsection{Robustness Checks}

We next perform a series of tests using alternative models and variable specifications to demonstrate the robustness of our results.

\section{Validity of Before-After Analysis}

Our before-after analysis essentially creates a difference-in-differences (DD) framework. We test the validity of the DD design by focusing on a shorter time window, 2015Q1 to 2018Q2. While many states had their ESSA plans approved before the end of the 2017-2018 school year (i.e., June 15, 2018), eight states received approvals for the plans after June 15, $2018^{9}$. In the analysis of the short time window, we perform an additional DD estimation by using 2017Q2 as the event time and schools in the states that had not signed ESSA in the time window as the control group. Shortening the time window allows us to confirm immediate effects of ESSA. In Table 3, columns (1) and (2) report results for the specifications where the key independent variable is ESSA, which continue to demonstrate that the ESSA sign-off is negatively associated with school crowdfunding performance, reflected through both Amount Raised and Proportion Funded. In columns (3) and (4), the coefficients of the interaction term, After $\times$ Treated, are negative at the five-percent significance level, suggesting that the finding holds with the alternative DD design in a short time window. In columns (5) and (6), the coefficients of the interaction term, Pre-period $\times$ Treated, pick up differences in the trend of crowdfunding performance, before the shift between ESSA-Implemented (treated) and ESSA-NotImplemented (control) groups. The statistically-insignificant estimates suggest that the parallel-trend assumption cannot be rejected when we use either Amount Raised or Proportion Funded as the dependent variable. In other words, in the absence of the treatment (ESSA), the difference between our treatment and control groups is roughly constant over time.

\section{Donor Awareness and DDD Analysis}

A potential problem with our before-after analysis is that donors may not be aware when the state ESSA plan was passed, thus other factors unrelated to the policy change might affect the donations contributed by the lesser-aware fraction of the population. To further refine the subgroup of the population affected by the policy change (i.e., the treatment group), we construct a Difference-in-Difference-in-Differences (DDD) framework including donors' awareness of the policy. To measure donors' awareness of ESSA, we

\footnotetext{
${ }^{9}$ These states include California, Maine, New Hampshire, Pennsylvania, Utah, Virginia, and West Virginia
}

gather data on the relative volume of search traffic for terms related to ESSA $^{10}$ from Google Trends ${ }^{11}$. The distribution of relative search volume by state is shown in Figure 1(C). We then use a binary variable to indicate whether donations raised by schools are mainly sourced from states with high interest in the searched terms. Specifically, we code the variable Awareness as 1 if the school has more than half of its funds raised from donors in the states whose interest indices are higher than the median in a given year. As shown in Figure 1(D), coefficients of ESSA $\times$ Awareness for Amount Raised and Proportion Funded are significantly negative; the coefficient of ESSA $\times$ Awareness for Local Amount is significantly positive and that for Outside Amount is significantly negative. This suggests that donors from states with higher awareness of ESSA give even lower amounts and allocate a larger portion of their donations locally.

\section{ESSA Announcement as an Alternative Shock}

While we find that donor awareness strengthens the effect of ESSA on school crowdfunding performance, another possibility is that donors may not know or mentally register when ESSA is signed into effect in each state. To address this possibility, we use an alternate shock - the widely-acknowledged ESSA announcement date, Dec $12,2015^{12}$ and code the binary variable Announced to be 1 for the period after Dec 12, 2015. We use the variable of donor awareness to separate treated (Awareness $=1$ ) and control (Awareness $=0)$ groups. As shown in Figure 1(E), the trends of school crowdfunding performance (reflected by the proportion of fully funded projects) for treated (the red line) and control (the blue line) groups are close with each other before the policy announcement and split after 2015, providing preliminary evidence that the ESSA announcement is associated with school crowdfunding performance. Our empirical results also show that the the findings remain consistent whether we use the date of sign-off for each state's plan or the main announcement date as the shock.

\section{Analyses at the Donation Level}

To augment our analysis, we compile a donation-level dataset with each donation record including information of the donor, project, and donation amount. Focusing on the period of 2011 to

\footnotetext{
${ }^{10}$ We search for the term "ESSA" and "Every Student Succeeds Act", and excluded irrelevant terms to make sure that the results are relevant to the policy. The search period is over the $12 / 1 / 2015$ to $3 / 31 / 2017$ time period, which covered the peak volume in search traffic for the ESSA-related terms.

${ }^{11}$ Google Trends is a public Web facility of Google, Inc., which is based on Google Search.

${ }^{12}$ To retain more pre-announcement periods, we perform this analysis over the period from 2011 to 2019.
} 
Table 3. Checks for Validity of Main DID Design

\begin{tabular}{|c|c|c|c|c|c|c|}
\hline & \multicolumn{6}{|c|}{ Dependent variable: } \\
\hline & $\begin{array}{l}\text { Amount Raised } \\
\text { (1) }\end{array}$ & $\begin{array}{l}\text { Proportion Funded } \\
\text { (2) }\end{array}$ & $\begin{array}{c}\text { Amount Raised } \\
\text { (3) }\end{array}$ & $\begin{array}{l}\text { Proportion Funded } \\
\text { (4) }\end{array}$ & $\begin{array}{c}\text { Amount Raised } \\
\text { (5) }\end{array}$ & $\begin{array}{c}\text { Proportion Funded } \\
\text { (6) }\end{array}$ \\
\hline ESSA & $\begin{array}{l}-0.216^{* * *} \\
(0.076)\end{array}$ & $\begin{array}{c}-0.073^{* * *} \\
(0.024)\end{array}$ & & & & \\
\hline After $\times$ Treated & & & $\begin{array}{c}-0.047^{* *} \\
(0.023)\end{array}$ & $\begin{array}{l}-0.010^{* *} \\
(0.005)\end{array}$ & & \\
\hline Pre-period $\times$ Treated & & & & & $\begin{array}{c}-0.00002 \\
(0.0001)\end{array}$ & $\begin{array}{c}0.00002 \\
(0.00002)\end{array}$ \\
\hline Control Variables & $\mathrm{Y}$ & $\mathrm{Y}$ & $\mathrm{Y}$ & $\mathrm{Y}$ & $\mathrm{Y}$ & $\mathrm{Y}$ \\
\hline School, State, Year, Quarter (FE) & $\mathrm{Y}$ & $\mathrm{Y}$ & $\mathrm{Y}$ & $\mathrm{Y}$ & $\mathrm{Y}$ & $\mathrm{Y}$ \\
\hline Observations & 321,484 & 321,484 & 321,484 & 321,484 & 209,444 & 209,444 \\
\hline $\mathrm{R}^{2}$ & 0.372 & 0.407 & 0.372 & 0.407 & 0.446 & 0.471 \\
\hline Adjusted $\mathrm{R}^{2}$ & 0.212 & 0.256 & 0.212 & 0.255 & 0.235 & 0.270 \\
\hline
\end{tabular}

2019, we use a similar empirical framework to test the effects of ESSA announcment on the donation amount at the donation level instead of school level, as in our main analysis. In brief, our findings continue to hold when we alter the level of analysis from aggregate (school) to granular (donation).

\section{Discussion}

Our analysis finds that an unintended consequence of the announcement of ESSA was a significant decline in the donations schools received through DonorsChoose.org. It appears that the knowledge of signing of the act diminished the overall eagerness of donors to fund teachers' projects. With increasing evidence of teachers going above and beyond their responsibilities to pay for school supplies and initiatives themselves, a voluntary donor-supported solution that eases teachers burdens, like Donorschoose, also appears to be affected when the policy announcement is made.

One possible explanation for our observation is the shift in perception of needs from private citizens. When standards are strict, and schools are struggling to meet the demands, private donors might feel an obligation to contribute to the gaps in resources. When standards are relaxed, this moral obligation and intent to contribute could diminish. By the same logic, federal laws that include provisions that impact accountability, and transparency of school administration might shift donors beliefs in a non-trivial way. For instance, one view is that NCLB made it strict that each state had to meet federal standards, but they gave states less flexibility in how they could go about achieving the goals. When ESSA gets passed, there is more flexibility for school districts and policy makers in setting student goals for states. So, the burden on states goes lower and private donors might perceive that they do not need to contribute since schools are likely to get a longer leash to set and meet education standards.
Interestingly, we find that donations became more local in nature after the act is signed off. That is, not only did the measure affect how much people give but also how donors distributed their donations. Donors from states with higher awareness of ESSA gave even lower amounts and allocated a larger portion of their donations locally. Our results remain consistent whether we use the state-specific approval dates or the overall announcement date as the event. Our findings also remain consistent when we alter the level of analysis from the aggregate level (school) to the granular level (donation).

It is well known that schools with higher proportions of students with low SES have fewer resources to begin with. Unfortunately, our results suggest that potentially well-intentioned external events like ESSA being signed into law might cause grassroots donors to contribute less than they usually do. So, the school districts with low SES students are likely to experience this effect disproportionately.

Our study has important implications for the public education system. For public schools hoping to raise funds online, it is important to remind donors in project descriptions that while the effects of government measures such as ESSA only gradually trickle down to the schools over time, teachers who are close to the ground reality know first-hand the immediate needs of their students. Donors hoping to help schools truly in need should realize that if donors only contributed to projects in their school districts, then wealthy school districts will receive the most funding for their projects. For online fundraising platform designers, our findings reveal that the hyper-local nature of the donations on such platforms intensifies the rich-gets-richer problem in public education. Given this, it is important for platforms to use nudges such as email promotions wisely, especially around the announcements of governmental measures. Instead of showing potential donors only projects from their zip 
codes and states, it might be prudent to expose donors from wealthy school districts to projects initiated by teachers from schools in poorer school districts. Finally, for education policy makers, our findings serve as a reminder of the tendency of people to focus on the needs of their immediate communities. Therefore, platforms like DonorsChoose, no matter how well-intentioned and helpful for meeting teachers' immediate needs, are not a replacement for comprehensive policies directed at addressing the needs of low socio-economic status students, families and communities.

\section{References}

[1] B. D. Baker, Educational Inequality and School Finance: Why Money Matters for America's Students. ERIC, 2018.

[2] D. Farrie and M. Johnson, "Newark public schools: Budget impacts of underfunding and rapid charter growth.," Education Law Center, 2015.

[3] T. Walker, "Teacher spending on school supplies: A state-by-state breakdown," Nea Today, 2019.

[4] D. I. Burnette, "Your guide to ESSA's new school-by-school spending mandate," Education Week, 2019.

[5] R. Bekkers and P. Wiepking, "A literature review of empirical studies of philanthropy: Eight mechanisms that drive charitable giving," Nonprofit and voluntary sector quarterly, vol. 40, no. 5, pp. 924-973, 2011.

[6] P. G. Warr, "The private provision of a public good is independent of the distribution of income," Economics letters, vol. 13, no. 2-3, pp. 207-211, 1983.

[7] J. Andreoni, "Impure altruism and donations to public goods: A theory of warm-glow giving," The economic journal, vol. 100, no. 401, pp. 464-477, 1990.

[8] J. Andreoni, "An experimental test of the public-goods crowding-out hypothesis," The American Economic Review, pp. 1317-1327, 1993.

[9] P. Younkin and V. Kuppuswamy, "The colorblind crowd? founder race and performance in crowdfunding," Management Science, vol. 64, no. 7, pp. 3269-3287, 2018.

[10] M. Lin and S. Viswanathan, "Home bias in online investments: An empirical study of an online crowdfunding market," Management Science, vol. 62, no. 5, pp. 1393-1414, 2016.

[11] G. Burtch, A. Ghose, and S. Wattal, "The hidden cost of accommodating crowdfunder privacy preferences: A randomized field experiment," Management Science, vol. 61, no. 5, pp. 949-962, 2015.

[12] Y. Hong, Y. Hu, and G. Burtch, "Embeddedness, pro-sociality, and social influence: Evidence from online crowdfunding," MIS Quarterly, vol. 42, no. 4, pp. 1211-1224, 2018.

[13] G. Burtch, A. Ghose, and S. Wattal, "An empirical examination of the antecedents and consequences of contribution patterns in crowd-funded markets," Information Systems Research, vol. 24, no. 3, pp. 499-519, 2013.
[14] K. Kim and S. Viswanathan, "The'experts' in the crowd: The role of experienced investors in a crowdfunding market," MIS Quarterly, vol. 43, no. 2, pp. 347-372, 2019.

[15] C. L. Exley, "Using charity performance metrics as an excuse not to give," Management Science, vol. 66, no. 2, pp. 553-563, 2020.

[16] J. B. Kessler and K. L. Milkman, "Identity in charitable giving," Management Science, vol. 64, no. 2, pp. 845-859, 2018.

[17] D. Neal and D. W. Schanzenbach, "Left behind by design: Proficiency counts and test-based accountability," The Review of Economics and Statistics, vol. 92, no. 2, pp. 263-283, 2010.

[18] J. Lee, "Input-guarantee versus performance-guarantee approaches to school accountability: Cross-state comparisons of policies, resources, and outcomes," Peabody Journal of Education, vol. 81, no. 4, pp. 43-64, 2006.

[19] M. Elsayed and C. H. Roch, "Unintended consequences: The effect of school accountability on teacher supply," Available at SSRN 3067351, 2017.

[20] S. M. Williams and R. O. Welsh, "Essa and school improvement: Principal1 preparation and professional development in a new era of education policy," Journal of School Leadership, vol. 27, no. 5, pp. 701-724, 2017.

[21] A. De Wit and R. Bekkers, "Government support and charitable donations: A meta-analysis of the crowding-out hypothesis," Journal of Public Administration Research and Theory, vol. 27, no. 2, pp. 301-319, 2016.

[22] B. Verschuere and J. De Corte, "The impact of public resource dependence on the autonomy of NPOs in their strategic decision making," Nonprofit and Voluntary Sector Quarterly, vol. 43, no. 2, pp. 293-313, 2014.

[23] A. De Wit, R. Bekkers, and M. Broese van Groenou, "Heterogeneity in crowding-out: When are charitable donations responsive to government support?," European Sociological Review, vol. 33, no. 1, pp. 59-71, 2017.

[24] P. Dekker and L. Halman, The values of volunteering: Cross-cultural perspectives. Springer Science \& Business Media, 2003.

[25] L. Dahlberg, "Interaction between voluntary and statutory social service provision in sweden: a matter of welfare pluralism, substitution or complementarity?," Social Policy \& Administration, vol. 39, no. 7, pp. 740-763, 2005.

[26] I. Stadelmann-Steffen, "Social volunteering in welfare states: Where crowding out should occur," Political Studies, vol. 59, no. 1, pp. 135-155, 2011.

[27] P. B. Cornelius and B. Gokpinar, "The role of customer investor involvement in crowdfunding success," Management Science, vol. 66, no. 1, pp. 452-472, 2020.

[28] Q. Gao, M. Lin, and D. Wu, "Educational crowdfunding and student performance: An empirical study," Georgia Tech Scheller College of Business Research Paper, no. 18-26, pp. 19-10, 2020.

[29] J. Meer, "Effects of the price of charitable giving: Evidence from an online crowdfunding platform," Journal of Economic Behavior \& Organization, vol. 103, pp. 113-124, 2014. 